\title{
Frequency of Tubal Ectopic Pregnancy and Mode of Management at Al-Thawra General Modern Hospital
}

\section{Belquis AJ and Dikrayat $\mathrm{H}$}

Obstetrics and Gynecology Department, Yemen

Corresponding author: Belquis AJ, Obstetrics and Gynecology, Yemen, Tel: + 967-548-2267; E-mail: bilaljailani@yahoo.com

Received date: January 16, 2017; Accepted date: February 04, 2017; Published date: February 14, 2017

Copyright: (C) 2017 Belquis AJ, et al. This is an open-access article distributed under the terms of the Creative Commons Attribution License, which permits unrestricted use, distribution, and reproduction in any medium, provided the original author and source are credited.

Citation: Belquis AJ, Dikrayat H. Frequency Of Tubal Ectopic Pregnancy And Mode Of Management At Al-Thawra General Modern Hospital. Crit Care Obst Gyne. 2017, 3:1.

\section{Abstract}

Objective: To determine the frequency of tubal ectopic pregnancy and to evaluate the epidemiological and common predisposing factors in cases study. To determine the mode of management of tubal ectopic pregnancy.

Study Design: This is a prospective descriptive analytic study carried out from 1 January 2013 until 31 December 2013 at obstetric and gynecological unit at Al-Thawra Hospital in Sana'a, Yemen.

Results: Total number of deliveries from the 1st of January 2013 till the 31st of December 2013, were a total of 9330 deliveries, out of which 103 women had tubal ectopic pregnancy creating an incidence of $1.1 \%$ of the total deliveries with a ratio of $11 / 1000$ live births. The mean age of the patients was 27.8 yrs and ranged between 17-40 years of age. It was most common in multipara with a percentage of $78.6754 .4 \%$ of women were Qat chewers and smokers. It was more commonly found in women of low economic status with $90.3 \%$. $30.1 \%$ of women with it had a history of abortion, $70.9 \%$ had a history of pelvic inflammatory disease, $20.8 \%$ had a history of an abdominopelvic surgery, $11.7 \%$ were using intrauterine device and $5.8 \%$ were using progesterone-only pills, $1.9 \%$ had a history of tubal sterilization, $88.3 \%$ presented with abdominal pain, $72.8 \%$ gave a history of amenorrhea, $63.1 \%$ presented with vaginal bleeding, $79.6 \%$ presented with hemodynamic instability, $86.5 \%$ were treated surgically, and $14.5 \%$ were treated medically using Methotrexate. The surgical treatment was salpingectomy in $90.4 \%$, and $6.6 \%$ was salpingostomy. There were no maternal mortalities.

Conclusion: The most common risk factors found in patients with tubal ectopic pregnancy were previous abortions and PID. The majority of the patients were treated surgically as they were lately presented in a state of hemodynamic instability. $14.5 \%$ were treated medically and this proved to be very effective.

Keywords: Ectopic pregnancy; Fertility; Methotrexate

\section{Introduction}

Tubal ectopic pregnancy is a common life-threatening emergency in pregnancy and the leading cause of death in the first trimester [1,2]. It results in significant morbidity for the mother, and inevitable loss of pregnancy [3]. Tubal ectopic pregnancy is an important cause of maternal morbidity and mortality especially in developing countries where the majority of the patients tend to present lately with rupture ectopic and hemodynamic compromise. The risk of death from extra-uterine pregnancy is 10 times more than that of vaginal delivery, and 50 times greater than induced abortion [4]. Ectopic pregnancy is defined as a pregnancy where the implantation of the blastocyst occurs outside the uterine cavity, most frequently within the fallopian tube (ampullary, ischemic, and interstitial portions of the tube). The incidence of ectopic pregnancy varies from country to country, and within the same geographical regions, depending on the risk factors in the population concerns [5]. The incidence in the western world ranges between 1-3\% of all pregnancies [6,7], in Saudi Arabia the prevalence is between $0.58-1.13 \%[8,9]$. Several risk factors for ectopic pregnancy have been identified, including a history of pelvic inflammatory disease, smoking at the time of conception, previous ectopic pregnancy, previous pelvic surgery, induction of ovulation, and intrauterine device usage. An understanding of the risk factors for ectopic pregnancy assists in a more rapid diagnosis, good result in reduction of need of surgery, and suggesting actions to improve prognosis [10]. An early and reliable diagnosis of ectopic pregnancy avoids the high incidence of maternal morbidity and mortality, and preserves future fertility [11]. Nowadays, the use of radio-immune assay for studying serum beta human chorionic gonadotropin ( $\beta \mathrm{HCG}$ ), the use of pelvic ultrasonography mainly transvaginal sonography, and use of diagnostic laparoscopy enables the gynecologist to diagnose ectopic pregnancy in an early stage before the beginning of any complications [12,13]. In most cases of ectopic pregnancy, surgical intervention is mandatory because of life-threatening intraperitoneal bleeding. Enraptured ectopic pregnancy can be treated by operation, medically, or by careful observation. Ectopic pregnancy is a tragedy of reproduction, and a form of reproductive failure in index pregnancy of effected women. Such women have a $7-15 \%$ chance of recurrence, and only $40-60 \%$ 
chance of conceiving after surgery [14]. Ectopic pregnancy presents a major health problem for women of childbearing age, and if not treated vigorously and early enough it may be fatal and is of immerse concern to reproductive health and is associated with significant maternal morbidity and mortality. The aim of this study is to find the magnitude of ectopic pregnancy in our country, and to determine some of the epidemiological and common risk factors in the case study.

\section{Objective}

To determine the incidence of tubal ectopic pregnancy in AlThawra general modern hospital. To determine epidemiological and common risk factors in the cases studied. To determine the mode of management of tubal ectopic pregnancy.

\section{Methodology}

\section{Study design}

This is a prospective, descriptive, analytic study done from January 1st December 31st 2013, carried out in the obstetric and gynecological department of Al-Thawra general modern hospital, which is the largest referral hospital in Sana'a, Yemen.

103 women were admitted to Al-Thawra general modern hospital with tubal ectopic pregnancy during the study period. The data was collected by interviewing face-to-face, and a direct questionnaire specially designed for the study which was filled by the author personally and includes the epidemiological and demographic characteristics, clinical presentation on admission, past history of PID, pelvic operation, contraception use, etc., and the type of treatment offered to women of tubal ectopic pregnancy.

All the data collected was coded and statistical analysis was performed using IBMP, and SPPS version 20. All the patients were consulted about their condition and consent was taken from them.

\section{Results}

\section{Incidence of Ectopic Pregnancy}



9227

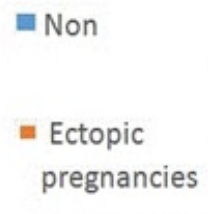

Figure 1 The mean age of the patients was $27.8 \mathrm{yrs}$ and ranged between 17-40 years of age. Most commonly found among the age group (25-29 Years) which is $39.8 \%$.

During the study period, from the 1st of January 2013 till the 31st of December 2013, there were a total of 9330 deliveries, out of which 103 women had tubal ectopic pregnancy creating an incidence of $1.1 \%$ of the total deliveries with a ratio of 11/1000 live births Figure 1.

Table 1 Distribution of Patients who had Ectopic Tubal Pregnancy according to age.

\begin{tabular}{|l|l|l|}
\hline Maternal Age & Frequency & Percentage\% \\
\hline$<20$ & 4 & 3.9 \\
\hline $20-24$ & 1.3 & 17.5 \\
\hline $25-29$ & 41 & 39.8 \\
\hline $30-34$ & 33 & 32 \\
\hline $35 \geq 39$ & 7 & 6 \\
\hline Total & 103 & 100 \\
\hline
\end{tabular}

$54.4 \%$ of woman who had ectopic pregnancy were Qat chewers and smokers as shown in Table 2.

Table 2 Social habits of woman who had Ectopic Pregnancy.

\begin{tabular}{|l|l|l|}
\hline Social Habits & Frequency & Percentage\% \\
\hline Cheweing Qat & 28 & 27.2 \\
\hline Smoking & 5 & 4.9 \\
\hline Both Cheweing \& Smoking & 56 & 54.4 \\
\hline NON & 14 & 13.6 \\
\hline Total & 103 & 100 \\
\hline
\end{tabular}

Incidence of Ectopic Pregnancy was found higher among woman of low social economic status with a percentage of 90.3\% as shown in Table 3.

Table 3 Social economic status with Ectopic Pregnancy.

\begin{tabular}{|l|l|l|}
\hline Social Economic & Frequency & Percentage $\%$ \\
\hline Status & & \\
\hline Low & 93 & 90.3 \\
\hline High & 10 & 9.7 \\
\hline Total & 103 & 100 \\
\hline
\end{tabular}

Tubal ectopic pregnancy was found most common in multipara with a percentage of 78.67 as shown in Table 4. Regarding the past obstetric and gynecological history of the 103 patients, $67 \%$ had a past history of abortion, $69.9 \%$ had a history of PID, $28.2 \%$ had a history of pelviabdominal surgery, $6.8 \%$ had a previous tubal ectopic pregnancy, $4.9 \%$ had a history of infertility, $4.9 \%$ went under induction of ovulation, $19.4 \%$ were using contraception of these $5.8 \%$ were using maniple, $11.7 \%$ were using IUD and $1.9 \%$ had tubal sterilization. As shown in Table 5.

Table 4 Distribution of Patients with Ectopic Pregnancy according to parity. 


\begin{tabular}{|l|l|l|}
\hline Parity & Frequency & Percentage\% \\
\hline Nilipara & 22 & 21.4 \\
\hline Multipara & 81 & 78.6 \\
\hline Total & 103 & 100 \\
\hline
\end{tabular}

Table 5 Risk factors associated with Patients of Ectopic Pregnancy during the study period.

\begin{tabular}{|l|l|}
\hline Risk Factor & Number \\
\hline History of PID & 72 \\
\hline History of abortion & 69 \\
\hline History of bdominopelvic surgery & 29 \\
\hline Intra-uterine device & 12 \\
\hline History of infertility & 5 \\
\hline History of induction of ovulation & 5 \\
\hline Progesterone-only pills & 6 \\
\hline Tubal sterilization & 2 \\
\hline
\end{tabular}

Table 6 Mode of Presentation of Patients with Tubal Ectopic Pregnancy.

\begin{tabular}{|l|l|l|}
\hline Presentation & Number & Percentage \\
\hline Abdominal pain & 91 & $88.50 \%$ \\
\hline Amenorrhea & 75 & $72.80 \%$ \\
\hline Vaginal bleeding & 65 & $63.10 \%$ \\
\hline
\end{tabular}

Table 7 Mode of Management of Tubal Ectopic Pregnancy.

\begin{tabular}{|l|l|l|l|}
\hline Mode & Number & Percentage & \\
\hline Surgical & 88 & $86.50 \%$ & \\
\hline Medical & 15 & $14.56 \%$ & \\
\hline
\end{tabular}

Table 8 Surgical Management Types.

\begin{tabular}{|l|l|l|l|}
\hline Type & & Number & Percentage \\
\hline Salpingectomy & & 83 & $93.40 \%$ \\
\hline Salpingectomy & & 5 & $6.60 \%$ \\
\hline Laparoscopy & & 0 & $0 \%$ \\
\hline
\end{tabular}

Regarding the clinical presentation of patients with tubal ectopic pregnancy, most of them (88.5\%) were presented with abdominal pain, the majority of them had severe lower abdominal pain, and $82.7 \%$ were hemodynamically unstable. $72.8 \%$ gave a history of amenorrhea of 5-6 weeks, and $63 \%$ were presented with vaginal bleeding. As shown in Table 6 .

The 103 women who had ectopic pregnancy, $20.3 \%$ of them were hemodynamically stable. Out of these, $14.56 \%$ were treated medically using $50 \mathrm{mg}$ injections of methotrexate and presented a positive outcome, and $86.5 \%$ were treated

surgically. Out of those who were treated surgically, $93.4 \%$ had salpingectomy and $6.6 \%$ had salpingostomy. No patients had laparoscopy. As shown in Table 7.

There were no maternal mortalities during the study period.

\section{Discussion}

Ectopic pregnancy is a common life-threatening emergency in pregnancy and a leading cause of pregnancy death in the first trimester $[15,16]$. It results in significant morbidity for the mother and inevitable loss of pregnancy [1,2,3]. Ectopic pregnancy is major cause of maternal morbidity and mortality, especially in developing countries where the majority of patients tend to present late with a ruptured form and hemodynamic compromise. During the study period from Jan. 1st-Dec. 31st 2013 , the incidence of tubal ectopic pregnancy was $1.1 \%$ with a ratio of $11 / 1000$ live births. The incidence was similar to a study which was performed in Saudi Arabia $[17,18]$ and a study performed by Mehboob $\mathrm{U}$ done in Pakistan.

In the USA, the rate is increasing annually and is approaching epidemic proportion. The reported incidence in 1993 ranged from $1 / 80-1 / 200$ live births [19]. The steady increase of ectopic pregnancy in the USA, as well as in several European countries during the past 25 years, could be attributed to an increased incidence of salpingitis, a major risk, as well as improved diagnostic techniques [20]. In this study, the incidence of ectopic pregnancy is lower than that of developing countries being nearly similar to the incidence of developed countries 20 years back. This could be attributed to the fact that the etiological factors that have increased the incidence of ectopic pregnancy are less common in our society. The incidence of ectopic pregnancy was found most commonly among multiparous women (78.6\%) and in the age group of $25-29$ years $(39.8 \%)$, the mean age being 27.8 years. This is similar to the study done by Romero et al [21]. Thus, the reproductive age is the risky period for having ectopic pregnancy and this correlates with the findings of Udigwee and et al [2], and Etuknwa [22]. In the study done by Manjui et al [23], it was found that incidence of ectopic pregnancy is higher among nilipara women, which conflicts with the result of our study [24]. In this study, it was found that ectopic pregnancy was more commonly found among women of low economic status (90\%). This may be due to not using contraception, liability to develop infection, or not seeking medical advice, as they are not capable of affording the treatment. In this study, the incidence of ectopic pregnancy was found higher among women who were smoking and chewing Qat (54.4\%). There is no study until now showing the association of Qat chewing and ectopic pregnancy. However, Qat chewing may interfere with the motility of the fallopian tube. $69.9 \%$ of women had a history of PID, $67 \%$ had a previous abortion, and $28.2 \%$ had a history of abdominopelvic surgery. These are the most common risk factors which are associated with ectopic pregnancy. These findings were similar to those found in a study done in a maternity hospital in France, which reported that PID, smoking at the time of conception, prior pelvic surgery, induction of ovulation, and maternal age are associated with ectopic pregnancy $[25,26]$. In a large case controlled study performed in France, it was proven that PID is a major cause of 
ectopic pregnancy [27]. The majority of women (80.6\%) in our study were not using contraception. In a study done by WHO, women who used contraception were less likely to have ectopic pregnancy when compared to non-users [28]. However, in women using progesterone-only pills or IUD the chance of the pregnancy being ectopic was increased. This is because the IUD reduces intra-uterine pregnancy by $99.5 \%$ and tubal implantation by $95 \%$ [29]. $90 \%$ of women in our study presented with abdominal pain, and $72.8 \%$ had a history of amenorrhea. This is similar to a study done by Tang BD et al, done in Libya $[30,31]$. Any woman who comes with pain and amenorrhea should raise the suspicion of ectopic pregnancy. Surgical management was the most common mode of management in our study, as 88 women underwent laparotomy since most of the patients $(90 \%)$ were presented late with rupture ectopic and internal bleeding. Salpingectomy was performed in $93.3 \%$ and salpingostomy in $6.4 \%$ to conserve tubal integrity and future fertility. In a study done by Miller \& Calendar 1993 [31], it was noted that salpingectomy is a treatment of choice, conservation and repair of tube is unwise even if it appears possible due to the danger of recurrence [28]. Laparoscopy is available in our hospital, but there is an absence of trained physicians to perform this. $14.6 \%$ were presented with intact ectopic and were treated with intramuscular methotrexate injections, this proved to be very effective. There were no maternal mortality during the study period.

\section{Conculsion}

Early diagnosis of tubal ectopic pregnancy is critically important in order to decrease maternal mortality and morbidity, and to preserve future fertility. Incidence of tubal ectopic pregnancy is $1.1 \%$ creating a ratio of $11 / 1000$ live births. Incidence is higher among women of low economic status and those who are smokers, and Qat chewers. PID, previous abortion, previous abdominopelvic surgery, use of intra-uterine device, and history of ectopic pregnancy were the most frequent risk factors associated with ectopic pregnancy. Most of the patients were presented late with ruptured ectopic pregnancy and hemodynamic instability and treated by salpingectomy Medical treatment of ectopic pregnancy is very effective and can conserve the tube and future fertility.

Due to various presentations of ectopic pregnancy, the physician should always be alert and consider ectopic pregnancy in any woman of reproductive age presented to the emergency room or out patient with history of amenorrhea, and abdominal pain. The first step should be to exclude ectopic Pregnancy. since early diagnosis will preserve fallopian tube and decrease maternal morbidity and mortality. Community based comprehensive health education programs, which focus on contraception, sex education, prevention, treatment of sepsis, and screening program for sexually transmitted diseases should be established.

\section{References}

1. Arup KM, Niloptal, Kakali SK, Pradip (2007) Ectopic pregnancy an analysis of 180 cases. J Indian Med Assoc 105: 308-314.
2. Shaw JT, Dry SK, Critchley Ho, Horne AW (2010) Current knowledge of the aetiology of human tubal ectopic pregnancy. Human Report Update 16: 32-44.

3. Udgiwe GO, Umeonihu OS, Mbuchu (2010) Ectopic pregnancy: A 5-year review of cases at Nnamdi Azikiwe University Teaching Hospital (NAUTH) Nnewi. Niger Med 51: 160-163.

4. Cunningham, Donald M, Grant, Levena, Gilstrap (1993) Ectopic pregnancy. William obstetrics by Applengton \& Hance 12: 691-715.

5. Stabile I, Grudzinski JG (1997) Ectopic pregnancy progress in Obstetrics and Gynecology. Edinburgh: Churchill Livinstone 11: 281-309.

6. Farquhar CM (1993) "Ectopic Pregnancy". The Lancet 366: 9485.

7. Farquhar CM (2005)“Ectopic Pregnancy”. 583-591.

8. Van Den Eeden SK, Shan J, Bruce C, Glasser M (2005) Ectopic Pregnancy rate and treatment utilization in a large managed care organization". Obstetrics and Gynecology 51: 1052-1057.

9. Aziz S, Al Wafi B, Al Swadi H (2011) "Frequency of ectopic pregnancy in a medical centre, Kingdom of Saudi Arabia". Journal of the Pakistan Medical Association 61: 221-224.

10. Al-Turki HA (2012) "Ectopic pregnancy: prevalence and risk factors in Saudi Arabian women". Saudi Medical Journals339:179-182.

11. Anorlu RI, Oluwole A, Abudu OO, Adebajo S (2001) Risk factors for ectopic pregnancy in Lagos, Nigeria. Acta Obstet Gynecol Scand 84: $184-188$.

12. Neary BA, Rose PG (1995) Complete response of persistent ectopic pregnancy to Dactinomycine after methotrexate failure. J Repord Med 85: 206-208.

13. Showky ZA, Badawy ET, Marwan E (1986) Conservative surgical treatment of tubal pregnancy factors affect future fertility. Int J of Fert 31: 187

14. Cacciatore B, Hakan U (1990) Diagnosis of ectopic pregnancy by vaginal ultrasonography in combination with discriminatory serum HCG level of 1000 IU/I. Brit J Obs and Gyn 97:144.

15. Aboyeji AP, ljaiya AA (2002) Trends in Ectopic Pregnancy in Ilorin, Nigeria. Nigerian Journal of Surgical Research 4: 1-2.

16. Eskandar M, Archibong E, Sadek AA, Adkunie A, Sobanade (2002) Ectopic pregnancy and seasonal variation: A retrospective study from southwestern region of Saudi Arabia. Bahrain MedBull 24: 330-334.

17. Archibong EL, Sobando AA (2000) Ectopic pregnancy in Abha, Saudi Arabia. A continuing corundum. Saudi Med J 24: 687-688.

18. Mehboob U, Mazhar SB (2006) Management of Ectopic Pregnancy: A two-year study. J Ayub Med Coll 18: 34-37.

19. Kaleeque F, Siddique R, Jafarey NS (2001) Ectopic pregnancies: a three years' study. J pak Med Assoc 51: 240 - 242.

20. Yekd TR, Mager JE (1999) A prospective eries of unruptured ectopic pregnancy to Dactinomycine injection with hyperosmlar glucose. Obst Gyn Peb 85: 206-208.

21. Lurie S, Katz Z (1998) Microscopic salpingitis is not an etiologic factor of tubal pregnancy' with intra-uterine devices. Int J Fert Menopaus Stud 39: 333-336.

22. Rommero Gutierrez (1994) clinical and ultra-sonographic data in ectopic pregnancy. Ginec-Obst-Mex 62: 157-160.

23. Brian M, Claren GR (1997) An unsual presentation of bilateral tubal pregnancy. Br J Clin Pray 47: 161-162. 
24. Majhi AK, Rpy N, Karmakar KS, Banerjee PK (2007) Ectopic pregnancy an analysis of 180 cases. J Indian Med Assoc 105: 308-312.

25. Mollison J, Porter M, Campell D, Bhattacharyra S (2005) Primary mode of delivery and subsequent pregnancy. Br J Obst Gynoecol 1112: 1061-1065.

26. Spira J, Collet $P$ (1993) Risk factors for ectopic pregnancy. Results of a case control study in the Rhone Alpes Region Contracep Fertil Sex 21: 307-312.

27. Coste J, Lauman B, Bremond A, Collet P, Spira J (1994) sexually transmitted diseases major causes ectopic pregnancy results from large case-control study. France Fertil Streil 62: 190-202.
28. Nyongo AO (1994) Smoking and reproductive health: cigarette smoking as risk factors in ectopic pregnancy. East AFr Med J 75: 32-34.

29. Etuknwa BT, Azuz OO, Peter Al, Ekandem GH, Olaifa K, et al (2012) Ectopic pregnancy: A Nigerian urban experience. Korean J. ObstetGynecol 55: 309-314.

30. Ezem BU, Essel EK, Otubu JA (1980) Ruptured tubal pregnancy in the Northern part of Nigeria. East Afr Med 57: 574-84.

31. WHO Task Force (1985) A multinational case controlled study of ectopic pregnancy. Clin Reprod Fertil 3: 131-134. 